\title{
Convergence analysis of Agarwal et al. iterative scheme for Lipschitzian hemicontractive mappings
}

Shin Min Kang ${ }^{1}$, Arif Rafiq ${ }^{2}$, Faisal Ali $^{3}$ and Young Chel Kwun ${ }^{4 *}$

\section{*Correspondence:}

yckwun@dau.ac.kr

${ }^{4}$ Department of Mathematics,

Dong-A University, Pusan, 614-714,

Korea

Full list of author information is

available at the end of the article

\begin{abstract}
In this paper, we establish strong convergence for the Agarwal et al. iterative scheme associated with Lipschitzian hemicontractive mappings in Hilbert spaces.

MSC: $47 \mathrm{H} 10 ; 47 \mathrm{~J} 25$

Keywords: Agarwal et al. iterative scheme; Lipschitzian mappings; continuous mappings; pseudocontractive mappings; Hilbert spaces
\end{abstract}

\section{Introduction and preliminaries}

Let $K$ be a nonempty subset of a Hilbert space $H$ and $T: K \rightarrow K$ be a mapping.

The mapping $T$ is called Lipschitzian if there exists $L>0$ such that

$$
\|T x-T y\| \leq L\|x-y\|, \quad \forall x, y \in K .
$$

If $L=1$, then $T$ is called nonexpansive and if $0 \leq L<1$, then $T$ is called contractive. The mapping $T: K \rightarrow K$ is said to be pseudocontractive (see, for example, [1, 2]) if

$$
\|T x-T y\|^{2} \leq\|x-y\|^{2}+\|(I-T) x-(I-T) y\|^{2}, \quad \forall x, y \in K,
$$

and it is said to be strongly pseudocontractive if there exists $k \in(0,1)$ such that

$$
\|T x-T y\|^{2} \leq\|x-y\|^{2}+k\|(I-T) x-(I-T) y\|^{2}, \quad \forall x, y \in K .
$$

Let $F(T):=\{x \in H: T x=x\}$, and the mapping $T: K \rightarrow K$ is called hemicontractive if $F(T) \neq \emptyset$ and

$$
\left\|T x-x^{*}\right\|^{2} \leq\left\|x-x^{*}\right\|^{2}+\|x-T x\|^{2}, \quad \forall x \in K, x^{*} \in F(T) .
$$

It is easy to see that the class of pseudocontractive mappings with fixed points is a subclass of the class of hemicontractions. For the importance of fixed points of pseudocontractions, the reader may consult [1].

In 1974, Ishikawa [3] proved the following result.

\section{Springer}

○2013 Kang et al.; licensee Springer. This is an Open Access article distributed under the terms of the Creative Commons Attribution License (http://creativecommons.org/licenses/by/2.0), which permits unrestricted use, distribution, and reproduction in any medium, provided the original work is properly cited. 
Theorem 1.1 Let $K$ be a compact convex subset of a Hilbert space $H$, and let $T: K \rightarrow K$ be a Lipschitzian pseudocontractive mapping. For arbitrary $x_{1} \in K$, let $\left\{x_{n}\right\}$ be a sequence defined iteratively by

$$
\left\{\begin{array}{l}
x_{n+1}=\left(1-\alpha_{n}\right) x_{n}+\alpha_{n} T y_{n}, \\
y_{n}=\left(1-\beta_{n}\right) x_{n}+\beta_{n} T x_{n}, \quad n \geq 1,
\end{array}\right.
$$

where $\left\{\alpha_{n}\right\}$ and $\left\{\beta_{n}\right\}$ are sequences satisfying

(i) $0 \leq \alpha_{n} \leq \beta_{n} \leq 1$;

(ii) $\lim _{n \rightarrow \infty} \beta_{n}=0$;

(iii) $\sum_{n=1}^{\infty} \alpha_{n} \beta_{n}=\infty$.

Then the sequence $\left\{x_{n}\right\}$ converges strongly to a fixed point of $T$.

Another iteration scheme has been studied extensively in connection with fixed points of pseudocontractive mappings.

In 2007, Agarwal et al. [4] introduced the new iterative scheme as in the following.

The sequence $\left\{x_{n}\right\}$ defined by, for arbitrary $x_{1} \in K$,

$$
\left\{\begin{array}{l}
x_{n+1}=\left(1-\alpha_{n}\right) T x_{n}+\alpha_{n} T y_{n}, \\
y_{n}=\left(1-\beta_{n}\right) x_{n}+\beta_{n} T x_{n}, \quad n \geq 1,
\end{array}\right.
$$

where $\left\{\alpha_{n}\right\}$ and $\left\{\beta_{n}\right\}$ are sequences in $[0,1]$, is known as the Agarwal et al. iterative scheme. In this paper, we establish the strong convergence for the Agarwal et al. iterative scheme associated with Lipschitzian hemicontractive mappings in Hilbert spaces.

\section{Main results}

We need the following lemma.

Lemma 2.1 [5] For all $x, y \in H$ and $\lambda \in[0,1]$, we have

$$
\|(1-\lambda) x+\lambda y\|^{2}=(1-\lambda)\|x\|^{2}+\lambda\|y\|^{2}-\lambda(1-\lambda)\|x-y\|^{2} .
$$

Now we prove our main results.

Theorem 2.2 Let $K$ be a compact convex subset of a real Hilbert space $H$, and let $T: K \rightarrow$ $K$ be a Lipschitzian hemicontractive mapping satisfying

$$
\|x-T y\| \leq\|T x-T y\|, \quad \forall x, y \in K .
$$

Let $\left\{\alpha_{n}\right\}$ and $\left\{\beta_{n}\right\}$ be sequences in $[0,1]$ satisfying

(ii) $\lim _{n \rightarrow \infty} \beta_{n}=0$;

(iii) $\sum_{n=1}^{\infty} \alpha_{n} \beta_{n}=\infty$;

(iv) $\lim _{n \rightarrow \infty} \alpha_{n}=1$.

For arbitrary $x_{1} \in K$, let $\left\{x_{n}\right\}$ be a sequence iteratively defined by

$$
\left\{\begin{array}{l}
x_{n+1}=\left(1-\alpha_{n}\right) T x_{n}+\alpha_{n} T y_{n}, \\
y_{n}=\left(1-\beta_{n}\right) x_{n}+\beta_{n} T x_{n}, \quad n \geq 1 .
\end{array}\right.
$$

Then the sequence $\left\{x_{n}\right\}$ converges strongly to the fixed point $x^{*}$ of $T$. 
Proof From Schauder's fixed point theorem, $F(T)$ is nonempty since $K$ is a convex compact set and $T$ is continuous, let $x^{*} \in F(T)$.

By using condition $(\mathrm{C})$, we have

$$
\begin{aligned}
\|x-T x\| & \leq\|x-T y\|+\|T x-T y\| \\
& \leq 2\|T x-T y\| .
\end{aligned}
$$

Using the fact that $T$ is hemicontractive, we obtain

$$
\left\|T x_{n}-x^{*}\right\|^{2} \leq\left\|x_{n}-x^{*}\right\|^{2}+\left\|x_{n}-T x_{n}\right\|^{2}
$$

and

$$
\left\|T y_{n}-x^{*}\right\|^{2} \leq\left\|y_{n}-x^{*}\right\|^{2}+\left\|y_{n}-T y_{n}\right\|^{2}
$$

With the help of (2.1), (2.3) and Lemma 2.1, we obtain

$$
\begin{aligned}
\left\|y_{n}-x^{*}\right\|^{2}= & \left\|\left(1-\beta_{n}\right) x_{n}+\beta_{n} T x_{n}-x^{*}\right\|^{2} \\
= & \left\|\left(1-\beta_{n}\right)\left(x_{n}-x^{*}\right)+\beta_{n}\left(T x_{n}-x^{*}\right)\right\|^{2} \\
= & \left(1-\beta_{n}\right)\left\|x_{n}-x^{*}\right\|^{2}+\beta_{n}\left\|T x_{n}-x^{*}\right\|^{2} \\
& -\beta_{n}\left(1-\beta_{n}\right)\left\|x_{n}-T x_{n}\right\|^{2} \\
\leq & \left(1-\beta_{n}\right)\left\|x_{n}-x^{*}\right\|^{2}+\beta_{n}\left(\left\|x_{n}-x^{*}\right\|^{2}+\left\|x_{n}-T x_{n}\right\|^{2}\right) \\
& -\beta_{n}\left(1-\beta_{n}\right)\left\|x_{n}-T x_{n}\right\|^{2} \\
= & \left\|x_{n}-x^{*}\right\|^{2}+\beta_{n}^{2}\left\|x_{n}-T x_{n}\right\|^{2}
\end{aligned}
$$

and

$$
\begin{aligned}
\left\|y_{n}-T y_{n}\right\|^{2}= & \left\|\left(1-\beta_{n}\right) x_{n}+\beta_{n} T x_{n}-T y_{n}\right\|^{2} \\
= & \left\|\left(1-\beta_{n}\right)\left(x_{n}-T y_{n}\right)+\beta_{n}\left(T x_{n}-T y_{n}\right)\right\|^{2} \\
= & \left(1-\beta_{n}\right)\left\|x_{n}-T y_{n}\right\|^{2}+\beta_{n}\left\|T x_{n}-T y_{n}\right\|^{2} \\
& -\beta_{n}\left(1-\beta_{n}\right)\left\|x_{n}-T x_{n}\right\|^{2} .
\end{aligned}
$$

Substituting (2.5) and (2.6) in (2.4), we obtain

$$
\begin{aligned}
\left\|T y_{n}-x^{*}\right\|^{2} \leq & \left\|x_{n}-x^{*}\right\|^{2}+\left(1-\beta_{n}\right)\left\|x_{n}-T y_{n}\right\|^{2} \\
& +\beta_{n}\left\|T x_{n}-T y_{n}\right\|^{2}-\beta_{n}\left(1-2 \beta_{n}\right)\left\|x_{n}-T x_{n}\right\|^{2} .
\end{aligned}
$$

Also, with the help of conditions (2.2) and (2.7), we have

$$
\begin{aligned}
& \left\|x_{n+1}-x^{*}\right\|^{2} \\
& \quad=\left\|\left(1-\alpha_{n}\right) T x_{n}+\alpha_{n} T y_{n}-x^{*}\right\|^{2}
\end{aligned}
$$




$$
\begin{aligned}
= & \left\|\left(1-\alpha_{n}\right)\left(T x_{n}-x^{*}\right)+\alpha_{n}\left(T y_{n}-x^{*}\right)\right\|^{2} \\
= & \left(1-\alpha_{n}\right)\left\|T x_{n}-x^{*}\right\|^{2}+\alpha_{n}\left\|T y_{n}-x^{*}\right\|^{2} \\
& -\alpha_{n}\left(1-\alpha_{n}\right)\left\|T x_{n}-T y_{n}\right\|^{2} \\
\leq & \left(1-\alpha_{n}\right)\left(\left\|x_{n}-x^{*}\right\|^{2}+\left\|x_{n}-T x_{n}\right\|^{2}\right)+\alpha_{n}\left(\left\|x_{n}-x^{*}\right\|^{2}\right. \\
& +\left(1-\beta_{n}\right)\left\|x_{n}-T y_{n}\right\|^{2}+\beta_{n}\left\|T x_{n}-T y_{n}\right\|^{2} \\
& \left.-\beta_{n}\left(1-2 \beta_{n}\right)\left\|x_{n}-T x_{n}\right\|^{2}\right) \\
= & \left\|x_{n}-x^{*}\right\|^{2}+\left(1-\alpha_{n}\right)\left\|x_{n}-T x_{n}\right\|^{2}+\alpha_{n} \beta_{n}\left\|T x_{n}-T y_{n}\right\|^{2} \\
& -\alpha_{n} \beta_{n}\left(1-2 \beta_{n}\right)\left\|x_{n}-T x_{n}\right\|^{2}+\alpha_{n}\left(1-\beta_{n}\right)\left\|x_{n}-T y_{n}\right\|^{2} \\
\leq & \left\|x_{n}-x^{*}\right\|^{2}+\left(4\left(1-\alpha_{n}\right)+\alpha_{n} \beta_{n}+\alpha_{n}\left(1-\beta_{n}\right)\right)\left\|T x_{n}-T y_{n}\right\|^{2} \\
& -\alpha_{n} \beta_{n}\left(1-2 \beta_{n}\right)\left\|x_{n}-T x_{n}\right\|^{2} \\
\leq & \left\|x_{n}-x^{*}\right\|^{2}+\theta \alpha_{n}\left\|T x_{n}-T y_{n}\right\|^{2}-\alpha_{n} \beta_{n}\left(1-2 \beta_{n}\right)\left\|x_{n}-T x_{n}\right\|^{2},
\end{aligned}
$$

because by (iv), there exists $n_{0} \in \mathbb{N}$ such that for all $n \geq n_{0}$,

$$
1-\alpha_{n} \leq \frac{\theta-1}{\theta+3}
$$

where $\theta>1$, which implies that

$$
4\left(1-\alpha_{n}\right)+\alpha_{n} \beta_{n}+\alpha_{n}\left(1-\beta_{n}\right) \leq \theta \alpha_{n}
$$

Hence (2.8) yields

$$
\begin{aligned}
& \left\|x_{n+1}-x^{*}\right\|^{2} \\
& \quad \leq\left\|x_{n}-x^{*}\right\|^{2}+\theta \alpha_{n} L^{2}\left\|x_{n}-y_{n}\right\|^{2}-\alpha_{n} \beta_{n}\left(1-2 \beta_{n}\right)\left\|x_{n}-T x_{n}\right\|^{2} \\
& \quad=\left\|x_{n}-x^{*}\right\|^{2}+\theta \alpha_{n} \beta_{n}^{2} L^{2}\left\|x_{n}-T x_{n}\right\|^{2}-\alpha_{n} \beta_{n}\left(1-2 \beta_{n}\right)\left\|x_{n}-T x_{n}\right\|^{2} \\
& \quad=\left\|x_{n}-x^{*}\right\|^{2}-\alpha_{n} \beta_{n}\left(1-\left(2+\theta L^{2}\right) \beta_{n}\right)\left\|x_{n}-T x_{n}\right\|^{2} .
\end{aligned}
$$

Now, by (ii), since $\lim _{n \rightarrow \infty} \beta_{n}=0$, there exists $n_{0} \in \mathbb{N}$ such that for all $n \geq n_{0}$,

$$
\beta_{n} \leq \frac{1}{2\left(2+\theta L^{2}\right)}
$$

With the help of (iii) and (2.12), (2.11) yields

$$
\left\|x_{n+1}-x^{*}\right\|^{2} \leq\left\|x_{n}-x^{*}\right\|^{2}-\frac{1}{2} \alpha_{n} \beta_{n}\left\|x_{n}-T x_{n}\right\|^{2},
$$

which implies that

$$
\frac{1}{2} \alpha_{n} \beta_{n}\left\|x_{n}-T x_{n}\right\|^{2} \leq\left\|x_{n}-x^{*}\right\|^{2}-\left\|x_{n+1}-x^{*}\right\|^{2},
$$


so that

$$
\frac{1}{2} \sum_{j=N}^{n} \alpha_{j} \beta_{j}\left\|x_{j}-T x_{j}\right\|^{2} \leq\left\|x_{N}-x^{*}\right\|^{2}-\left\|x_{n+1}-x^{*}\right\|^{2}
$$

The rest of the argument follows exactly as in the proof of theorem of [3]. This completes the proof.

Theorem 2.3 Let $K$ be a compact convex subset of a real Hilbert space $H$; let $T: K \rightarrow K$ be a Lipschitzian hemicontractive mapping satisfying condition $(C)$. Let $\left\{\alpha_{n}\right\}$ and $\left\{\beta_{n}\right\}$ be sequence in $[0,1]$ satisfying conditions (ii)-(iv).

Let $P_{K}: H \rightarrow K$ be the projection operator of $H$ onto $K$. Let $\left\{x_{n}\right\}$ be a sequence defined iteratively by

$$
\left\{\begin{array}{l}
x_{n+1}=P_{K}\left(\left(1-\alpha_{n}\right) T x_{n}+\alpha_{n} T y_{n}\right), \\
y_{n}=P_{K}\left(\left(1-\beta_{n}\right) x_{n}+\beta_{n} T x_{n}\right), \quad n \geq 1
\end{array}\right.
$$

Then the sequence $\left\{x_{n}\right\}$ converges strongly to a fixed point of $T$.

Proof The operator $P_{K}$ is nonexpansive (see, e.g., [2]). $K$ is a Chebyshev subset of $H$ so that $P_{K}$ is a single-valued mapping. Hence, we have

$$
\begin{aligned}
\left\|x_{n+1}-x^{*}\right\|^{2} & =\left\|P_{K}\left(\left(1-\alpha_{n}\right) T x_{n}+\alpha_{n} T y_{n}\right)-P_{K} x^{*}\right\|^{2} \\
& \leq\left\|\left(1-\alpha_{n}\right) T x_{n}+\alpha_{n} T y_{n}-x^{*}\right\|^{2} \\
& =\left\|\left(1-\alpha_{n}\right)\left(x_{n}-x^{*}\right)+\alpha_{n}\left(T y_{n}-x^{*}\right)\right\|^{2} \\
& \leq\left\|x_{n}-x^{*}\right\|^{2}-\alpha_{n} \beta_{n}\left(1-\left(2+\theta L^{2}\right) \beta_{n}\right)\left\|x_{n}-T x_{n}\right\|^{2} .
\end{aligned}
$$

The set $K=K \cup T(K)$ is compact and so the sequence $\left\{\left\|x_{n}-T x_{n}\right\|\right\}$ is bounded. The rest of the argument follows exactly as in the proof of Theorem 2.2. This completes the proof.

Example 2.4 The choice for the control parameters is $\alpha_{n}=\frac{n}{n+1}$ and $\beta_{n}=\frac{1}{n}$.

Remark 2.5 (1) We remove the condition $\alpha_{n} \leq \beta_{n}$ as introduced in [3].

(2) The condition $(C)$ is not new and it is due to [6].

\section{Competing interests}

The authors declare that they have no competing interests.

Authors' contributions

All authors read and approved the final manuscript.

\section{Author details}

'Department of Mathematics and RINS, Gyeongsang National University, Jinju, 660-701, Korea. ${ }^{2}$ Department of

Mathematics, Lahore Leads University, Lahore, Pakistan. ${ }^{3}$ Centre for Advanced Studies in Pure and Applied Mathematics, Bahauddin Zakariya University, Multan, 54000, Pakistan. ${ }^{4}$ Department of Mathematics, Dong-A University, Pusan, 614-714 Korea. 


\section{Acknowledgements}

The authors would like to thank the editor and referees for useful comments and suggestions. This study was supported by research funds from Dong-A University.

Received: 23 July 2013 Accepted: 5 September 2013 Published: 11 Nov 2013

\section{References}

1. Browder, FE: Nonlinear Operators and Nonlinear Equations of Evolution in Banach Spaces, Nonlinear Functional Analysis. Am. Math. Soc., Providence (1976)

2. Browder, FE, Petryshyn, WV: Construction of fixed points of nonlinear mappings in Hilbert spaces. J. Math. Anal. Appl. 20, 197-228 (1967). doi:10.1016/0022-247X(67)90085-6

3. Ishikawa, S: Fixed point by a new iteration method. Proc. Am. Math. Soc. 4, 147-150 (1974). doi:10.2307/2039245

4. Agarwal, RP, O'Regan, D, Sahu, DR: Iterative construction of fixed points of nearly asymptotically nonexpansive mappings. J. Nonlinear Convex Anal. 8, 61-79 (2007)

5. Xu, HK: Inequalities in Banach spaces with applications. Nonlinear Anal. 16, 1127-1138 (1991). doi:10.1016/0362-546X(91)90200-K

6. Liu, Z, Feng, C, Ume, JS, Kang, SM: Weak and strong convergence for common fixed points of a pair of nonexpansive and asymptotically nonexpansive mappings. Taiwan. J. Math. 11, 27-42 (2007)

10.1186/1029-242X-2013-525

Cite this article as: Kang et al.: Convergence analysis of Agarwal et al. iterative scheme for Lipschitzian

hemicontractive mappings. Journal of Inequalities and Applications 2013, 2013:525

\section{Submit your manuscript to a SpringerOpen ${ }^{\circ}$ journal and benefit from:}

- Convenient online submission

- Rigorous peer review

- Immediate publication on acceptance

Open access: articles freely available online

- High visibility within the field

- Retaining the copyright to your article 